\title{
Facing the pandemic in the dark: Psychopathic personality traits and life history strategies during COVID-19 lockdown period in different areas of China
}

\author{
Heng $\mathrm{Li}^{1} \cdot \mathrm{Yu} \mathrm{CaO}{ }^{2}$ \\ Accepted: 25 February 2021 / Published online: 1 March 2021 \\ (C) The Author(s), under exclusive licence to Springer Science+Business Media, LLC part of Springer Nature 2021
}

\begin{abstract}
The current research aims to examine variation in psychopathic personality traits and life history strategies during COVID-19 lockdown period in different areas of China. In Study $1(N=564)$, participants completed explicit measures of psychopathic traits and of life history strategy. To attenuate common method biases, Study $2(N=267)$ employed an alternative measure of psychopathy and an indirect measure of life history strategy, namely, future-discounting. Across two studies, we found consistent and significant evidence that participants from Wuhan, the initial epicenter of the pandemic, evidenced a faster life history strategy and a markedly higher level of psychopathic traits than did participants from Chongqing, which was less affected by the virus. Furthermore, a consistent pattern of correlation between life history strategy and psychopathy was observed across different groups of participants. We also replicated some previously reported studies but found that not all sex effects were consistent with life history in Chinese populations. Taken together, these findings suggest that individuals may show a high degree of variation in life history speed and psychopathic traits in response to unpredictable and adverse environments, which provide support for extended life history plasticity.
\end{abstract}

Keywords COVID-19 $\cdot$ Life history theory $\cdot$ Slow/fast strategy $\cdot$ Psychopathic personality traits $\cdot$ Lockdown

\section{Introduction}

The non-clinical concept of psychopathy is generally conceptualized as impaired empathy, extreme ego-centricity, and emotion dysregulation, accompanied by a socially deviant lifestyle (Cleckley, 1941; Garofalo, Neumann, Kosson, \& Velotti, 2020; Hare, 1991; Miller, Vize, Crowe, \& Lynam, 2019; Paulhus \& Williams, 2002). An immense body of studies investigated how underlying genetic and environmental factors influence psychopathic personality traits in children and adolescent samples (Taylor, Loney, Bobadilla, Iacono, \& McGue, 2003; Tuvblad et al., 2019). For instance, in a study involving 1090 monozygotic and dizygotic twin pairs at age 16-17, Larsson, Andershed, and Lichtenstein (2006)

Heng Li

leehem168@163.com

1 College of International Studies, Southwest University, Chongqing 400715, China

2 School of Foreign Languages, Zhongnan University of Economics and Law, Wuhan, China found that genetic effects explained approximately $40 \%$ of the variation in both the callous/unemotional and the impulsive/antisocial facets of psychopathic-like traits. While nonshared environmental effects can account for all the remaining variance, no significant shared environmental influences were observed in higher order psychopathic personality. Although such research provided some evidence for the etiology of the different psychopathic characteristics, there is still a paucity of information in the literature regarding the relationship between exposure to unpredictable and harsh socioecological conditions and psychopath.

From the perspective of Life History Theory, human or any living species have developed a set of psychological, behavioral, and physiological adaptations for survival and reproduction (Dunkel, Hertler, Mathes, \& de Baca, 2019; MacArthur \& Wilson, 1967; Stearns \& Rodrigues, 2020; Wilson, 1975). Individuals may enact different life history strategies, ranging along a slow-to-fast continuum, when they are faced with fitness optimization problems over the life course (Del Giudice, Gangestad, \& Kaplan, 2015; Figueredo, Menie, \& Jacobs, 2015; Griskevicius et al., 2013). For instance, people need to constantly estimate and to make the efficient allocation of energy and time resources in response to changes in 
major environmental pressures. There are two main strategies which have been extensively discussed in the evolutionary psychology literature. A faster life history strategy ( $\mathrm{r}-$ selected) emerged in an impoverished and unpredictable environment, and is associated with impulsive aggression, riskseeking, and opportunistic behavior (Belsky, Schlomer, \& Ellis, 2012; Kruger, Reischl, \& Zimmerman, 2008; Lu \& Chang, 2019; Richardson et al., 2020). For instance, Međedović (2019) compared Kosovo adolescents who grew up in a postconflict society with a control group from Serbia. The results showed that Kosovo participants, who experienced physical manifestations of intergroup conflict, were more likely to adopt a faster life-history strategy as evidenced through greater mating effort and a larger desired number of offspring than the control group. This pattern of results suggests that the hostile and dangerous environment leads to the emergence of a faster-life strategy pattern, supporting the Life History Theory. A slow life strategy (k-selected), on the other hand, is linked to impulsive control, risk aversion, and longterm goal pursuit (Sng, Neuberg, Varnum, \& Kenrick, 2017). For instance, Olderbak and Figueredo (2009) found that a slow life-history strategy is positively associated with the development of a secure attachment relationship and supportive communication patterns.

One strand research on Life History Theory is the work on the relationship between life history strategy and dark personality traits (Jonason, Webster, Schmitt, Li, \& Crysel, 2012; McDonald, Donnellan, \& Navarrete, 2012). Dark triad refers to a constellation of personality traits with malevolent connotations. The three traits are Machiavellianism (interpersonal manipulation), narcissism (extreme self-love), and psychopathy (incapacity to empathize) (Paulhus \& Williams, 2002). In a handful of published studies examining dark personality traits from an evolutionary perspective, a consistent finding is that psychopathy is a positive predictor of a faster life strategy as indicated by reduced self-control, short-term mating tendencies, and other development and manifestation of antisocial behavior (Griskevicius, Tybur, Delton, \& Robertson, 2011; Sherman, Figueredo, \& Funder, 2013). For instance, Jonason, Koenig, and Tost (2010) investigated the relationship between the Dark Triad traits and life history strategy using different and complementary measures. The results showed that whereas narcissism and Machiavellianism only correlated with some life history variables such as casual sex relationships, psychopathy seemed to be the best indicator of a fast life history strategy. Furthermore, Hurst and Kavanagh (2017) examined the links between life history strategies and internalizing and externalizing symptoms of psychopathology. They found that individuals adopting a faster life strategy evidenced higher levels of aggression and symptoms of psychopathology. Within an evolutionary framework, the relatively strong correlation between the fast end of the life history continuum and psychopathy might be due to biological adaption (Del Giudice, 2014). Therefore, although fast life behaviors are not necessarily benefit general health and wellbeing from a long-term perspective with some psychopathic traits (e.g., aggression, decreased empathy), they may be functionally adaptive for individuals in an unstable and unpredictable environment (e.g., earlier pubertal timing) (Crawford, 2000). Taken together, these findings suggest that Life History Theory can account for both clinical and nonclinical psychopathic traits.

Integrating two strands of research - namely, research investigating harsh environment conditions such as high rates of criminal violence (Copping \& Campbell, 2015), higher mortality and resource scarcity (Griskevicius et al., 2011), and childhood socioeconomic hardship (Sheppard, Pearce, \& Sear, 2016), leading to faster life history speeds and research investigating the relationship between life history strategy and psychopathy - the next step in progressing the literature is to examine how environmental harshness and unpredictability affect people's life history strategy and psychopathy and the associations between these variables. The COVID-19 pandemic provided researchers with a natural test case to understand the changes of personality traits responding to the environmental pressure and threats through life history regulation of social behaviors.

Since December 2019, Wuhan, the capital of Hubei province in central China, reported its first cluster of atypical pneumonia cases, which was later officially named COVID-19 by the World Health Organization. It became the initial epicenter of the coronavirus outbreak and was locked down from January 23rd to April 8th. Following the total lockdown, transportation such as trains, airports, and major highways and most communities in the city only kept one entrance and exit point open. Each household is allowed limited numbers of entrances and exits (Lau et al., 2020). During the lockdown period, there were a total of 50,008 confirmed cases of COVID-19 and 2571 deaths. ${ }^{1}$ Multiple studies have revealed physical and mental health toll at the peak of Wuhan's COVID-19 outbreak (Li et al., 2021; Zhong, Huang, \& Liu, 2021). For instance, Ni et al. (2020) found that about one-fifth of community-based adults and health professionals reported experiencing some levels of anxiety and depression. Compared to Wuhan, Chongqing, one of the largest municipalities in southwest China, was less affected by COVID-19. For instance, Chongqing did not go into a total lockdown but implemented a robust policy of social distancing. From January 23rd to April 8th, there were 576 confirmed cases of COVID-19 and 6 deaths in Chongqing. ${ }^{2}$ Thus, it can be seen

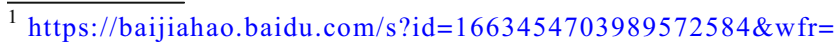
spider\&for $=\mathrm{pc}$

${ }^{2}$ http://wsjkw.cq.gov.cn/ztzl_242/qlzhxxgzbdfyyqfkgz/yqtb/202004/ t20200408 7018771.html
} 
that Wuhan faced greater environmental instability and harshness during the lockdown period than Chongqing.

In the evolutionary literature, the more unpredictable and adverse conditions propel individuals to enact a fast lifehistory strategy (Kruger, Fernandes, Cupal, \& Homish, 2019). Based on these findings, we first tested the prediction that individuals in Wuhan city would adopt a faster life history strategy and score higher on the psychopathy traits. In addition, the vast majority of research examining the correlation between life history strategy and psychopathy has been done on western, educated, industrialized, rich, and democratic (WEIRD) populations (Apicella, Norenzayan, \& Henrich, 2020). It is unclear whether these findings can generalize to non-WEIRD settings. Thus, the second aim of this paper is to test whether psychopathy is related to life history speed by using Chinese populations. Finally, prior work has indicated that in comparison to females, males show more sensitivity to the environmental parameters of harshness and unpredictability (Jonason, Li, Webster, \& Schmitt, 2009). The latter tend to evidence a fast life history strategy as an adaptive response to dangerous ecological conditions. Therefore, it can be expected that males will adopt a faster life strategy than females vis-àvis dark personality traits.

In the current research, two independent studies were conducted to test three sets of our predictions. Study 1 directly compared the patterns of life history strategies and the level of psychopathy between Wuhan and Chongqing participants and whether these two psychological constructs are correlated in both groups. Extending beyond the explicit measure of life history strategy in Study 1, Study 2 used an indirect measure of life history strategy and an alternative measure of psychopathy to test the same predictions. We believe that each study can solve limitations of the other to create a coherent and logical scheme and to attenuate common method biases associated with self-reported measures. In both studies, we aimed to replicate prior findings that men evidence a faster life history strategy and a higher level of psychopathic personality traits than women. Overall, we hope to offer converging evidence to support our central hypothesis that harsh and unpredictable environments exert concurrent effects on life history development and psychopathy.

\section{Study 1}

\section{Method}

\section{Participants}

We recruited our participants from Wenjuanxing (also called the Chinese version of Amazon Mechanical Turk, www.wjx. $\mathrm{cn}$ ), an online platform that provides professional online questionnaire survey in a large and wide pool of participants. Data obtained via Wenjuanxing surveys and experiments have been shown to be largely comparable to those collected via conventional means such as field studies and lab experiments in psychological science research (e.g., Buchtel et al., 2015; Chen et al., 2020; Lu, Liu, Liao, \& Wang, 2020). Data collection were conducted from February 5-10, 2020, the lockdown period of Hubei province. Each participant made an explicit agreement that their anonymized data might be used for scientific research and for publication purposes. We only included participants whose IP addresses were in Wuhan and Chongqing.

290 non-diseased members from Wuhan city (131 females; mean age $=28.8, S D=6.7$, age range $=18-40$ years $)$ and 274 non-diseased members from Chongqing city (129 females; mean age $=27.9, S D=7.5$, age range $=18-40$ years) filled out an anonymous questionnaire survey. There were no significant differences between the two groups in terms of age $(t=1.62, p>.05, \mathrm{CI}=[-0.193,1.993])$.

\section{Materials and Procedure}

Psychopathic traits were assessed with the Dirty Dozen measure of psychopathy (Jonason \& Webster, 2010). The Chinese version of the 4-item subscale had satisfactory reliability and promising construct validities as shown in previous research (e.g. $\alpha=0.757$; Geng, Sun, Huang, Zhu, \& Han, 2015). The subscale also showed adequate internal consistencies $(\alpha=$ 0.743), demonstrating that it is a reliable tool for assessing psychopathy. Participants were asked to indicate how much they agreed with statements such as "I tend to be cynical" and "I tend to lack remorse" on a 5-point Likert-type response scale ( 1 = strongly disagree, 5 = strongly agree).

Participants then completed the Mini-K, a 20-item measure which was used to gauge their life history strategy (Figueredo et al., 2006). The Chinese version of the Mini-K had good validity and satisfactory construct validities in a study of Chinese populations (Wang, Lin, Hou, \& Sun, 2017). The internal consistencies of the questionnaire were also good in the current study ( $\alpha=0.871)$. Participants were asked to rate their agreement with each item on a 5-point Likert-type response scale ( $1=$ not at all; $5=$ very much). The sample statements include "While growing up, I had a close and warm relationship with my biological mother" and "I often give emotional support and practical help to my friends". These items were averaged to create an index of each participant's life history strategy, with higher scores representing a slower life history strategy.

To ensure the quality of research subjects, we integrated an attention check question: "How much do you agree that zodiac signs affect your personality? Please select 'strongly disagree' for this item." Participants who were not attentively participating the survey were excluded from the final analysis. 


\section{Results and Discussion}

Table 1 summarizes the descriptive statistics for psychopathy and the Mini-K scores. For psychopathy scores, we performed a 2 (Group: Wuhan and Chongqing) by 2 (Gender: Male and Female) ANOVA. The main effect of Group was significant, $F(1,562)=39.39, p<.001, \eta_{\mathrm{p}}{ }^{2}=.07$, such that Wuhan participants scored higher on the trait measure of psychopathy $(M=2.72, S D=0.79)$ than Chongqing participants $(M=$ 2.33, $S D=0.72$ ), demonstrating a darker aspect of personality, $t(562)=6.31, p<.001, d=0.53,95 \% \mathrm{CI}=[0.2755,0.5245]$. The main effect of gender was also significant, $F(1,562)=$ $56.45, p<.001, \eta_{\mathrm{p}}{ }^{2}=.09$. This pattern of results suggests that male participants from Wuhan and Chongqing scored higher in self-reported psychopathy than their female counterparts, $t$ Wuhan $(288)=5.14, p<.001, d=0.61,95 \% \mathrm{CI}=[0.2838$, $0.6362] ; t$ Chongqing $(272)=5.49, p<.001, d=0.67$, $95 \% \mathrm{CI}=[0.2905,0.6157]$. Such findings are in line with multiple studies that male individuals evidence a higher level of psychopathic traits in comparison to female individuals (Figueredo et al., 2006; Geary, 2005; Jonason et al., 2010). However, there was no interaction between Group and Gender, $F<1$.

For the Mini-K scores, we also conducted a 2 (Group: Wuhan and Chongqing) by 2 (Gender: Male and Female) ANOVA. The main effect of Group was significant, $F(1$, $562)=31.90, p<.001, \eta_{\mathrm{p}}{ }^{2}=.06$, such that Wuhan participants, who had exposure to a more unstable and unpredictable environment, tended to adopt a faster life history strategy $(M=2.79, S D=0.75)$ than Chongqing participants $(M=$ 3.11, $S D=0.64)$ who were less affected by COVID-19, $t$ $(562)=5.44, p<.001, d=0.46,95 \% \mathrm{CI}=[-0.4357$, $-0.2043]$. The main effect of gender was also significant, $F$ $(1,562)=81.94, p<.001, \eta_{\mathrm{p}}{ }^{2}=.13$. This pattern of results suggests that male participants in both groups also showed more characteristic traits of fast life strategy than their female counterparts, $t$ Wuhan $(288)=5.41, p<.001, d=0.64$, $95 \% \mathrm{CI}=[-0.6272,-0.2928] ; t$ Chongqing $(272)=7.90$, $p<.001, d=0.94,95 \% \mathrm{CI}=[0.4129,0.6871]$. Such findings suggest that compared with women, men may be more sensitive to unpredictable, rapidly changing environment, which can promote the development of faster life history strategies for their survival and success (Del Giudice, 2009; Jonason, Zeigler-Hill, \& Baldacchino, 2017). However, there was no interaction between Group and Gender, $F<1$.

As expected, a consistent finding in both groups of participants was that psychopathic personality traits were negatively correlated with life history strategy indexed by the Mini-K (Wuhan: $r=-.52, p<.001$; Chongqing: $r=-.58, p<.001$ ).

Study 1 provided initial support for the idea that Wuhan participants, who were more affected by the COVID-19 pandemic, showed a markedly higher level of psychopathy and lived a higher faster life speed than their Chongqing counterparts. In addition, we also replicated the findings that there are potential gender differences in the interconnections between the variables as discussed above. To further test the robustness of these associations, we used other well-established measures of psychopathy and life history strategy. Its main purpose was to offer convergent validity evidence for our preliminary findings and to reduce the likelihood of common method biases associated with the single method.

\section{Study 2}

\section{Method}

\section{Participants}

As in Study 1, we also recruited our participants from Wenjuanxing. Data collection was conducted from February 11-15, 2020. Each participant made an explicit agreement that their anonymized data might be used for scientific research and for publication purposes. No IP addresses of the participants were the same with those in Study 1.

133 non-diseased members from Wuhan city (69 females; mean age $=26.3$, $\mathrm{SD}=6.8$, age range $=18$ 40 years) and 134 non-diseased members from Chongqing city ( 75 females; mean age $=27.1, \mathrm{SD}=7.0$, age range $=18-40$ years) were recruited to fill out an anonymous questionnaire survey. There were no significant differences between the two groups in terms of age $(t=0.95, p>.05, \mathrm{CI}=[-2.463,0.863])$.

Table 1 Descriptive statistics and sex difference tests

\begin{tabular}{|c|c|c|c|c|c|c|c|c|c|c|c|c|}
\hline & \multicolumn{6}{|c|}{ Psychopathy } & \multicolumn{6}{|c|}{ Life history strategy } \\
\hline & \multicolumn{2}{|c|}{ Overall } & \multicolumn{2}{|l|}{ Men } & \multicolumn{2}{|c|}{ Women } & \multicolumn{2}{|c|}{ Overall } & \multicolumn{2}{|l|}{ Men } & \multicolumn{2}{|c|}{ Women } \\
\hline & Mean & SD & Mean & SD & Mean & $\mathrm{SD}$ & Mean & SD & Mean & SD & Mean & $\mathrm{SD}$ \\
\hline Wuhan & 2.72 & 0.79 & 2.93 & 0.85 & 2.47 & 0.63 & 2.79 & 0.75 & 2.58 & 0.72 & 3.04 & 0.72 \\
\hline Chongqing & 2.33 & 0.72 & 2.54 & 0.79 & 2.09 & 0.53 & 3.11 & 0.64 & 2.85 & 0.58 & 3.40 & 0.57 \\
\hline
\end{tabular}




\section{Materials and Procedure}

Individual levels of psychopathic personality traits were assessed with the Chinese version of the Psychopathy Subscale from the Short Dark Triad Scale (SD3: Jones \& Paulhus, 2014). This 9-item questionnaire has sufficient psychometric quality in Chinese populations as demonstrated in previous validation research (e.g. $\alpha=0.83$; Geng et al., 2015). The instrument also showed adequate internal consistency in the current research $(\alpha=0.83)$. Sample items include "People often say I'm out of control" and "Payback needs to be quick and nasty". Participants provided their responses on a 5-point Likert type scale ranging from 1 ("strongly disagree") and 5 ("strongly agree").

We assessed life history strategy indirectly employing a monetary dilemma which has been widely used as a standard measurement technique in published research (e.g., Jonason et al., 2010). Respondents must choose between smallersooner and larger-later rewards in the exercise (Read \& Read, 2004). The two options were: "You can have 100 yuan now or 1000 yuan in a year. Which would you prefer?". The immediate payoff represented a fast life strategy, while the delayed payoff represented a slow life strategy.

\section{Results and Discussion}

$37.6 \%$ of Wuhan participants chose the immediate payoff in comparison to $11.2 \%$ of Chongqing participants (Fig. 1). We conducted a chi-square test for independence to determine whether the difference in responses was significant, which revealed a significant relationship: $\chi^{2}=25.26 ; p<0.001$; Cramer's V $=0.31, \mathrm{CI}=[0.1915,1.4152]$. These findings suggest that Wuhan participants had a faster life strategy than their Chongqing counterparts. Contrary to our expectation, men did not enact a faster life history strategy than women as shown in their options for the delayed rewards (Wuhan: $42.2 \%$ vs. $33.3 \%, p=0.29$ by Fisher's exact test; Chongqing: $16.9 \%$ vs. $6.7 \%, p=0.06$ by Fisher's exact test).

Table 2 summarizes the descriptive statistics for psychopathy and sex differences. We performed a 2 (Group: Wuhan and Chongqing) by 2 (Gender: Male and Female) ANOVA. The main effect of Group was significant, $F(1,265)=25.89$, $p<.001, \eta_{\mathrm{p}}{ }^{2}=.09$, such that Wuhan participants scored higher on the trait measure of psychopathy $(M=2.56, S D=$ $0.75)$ than Chongqing participants $(M=2.14, S D=0.64)$, demonstrating a darker aspect of personality, $t(265)=4.92$, $p<.001, d=0.60,95 \% \mathrm{CI}=[0.2510,0.5864]$. The main effect of gender was also significant, $F(1,265)=38.46, p<.001$, $\eta_{\mathrm{p}}{ }^{2}=.13$. This pattern of results suggests that male participants from Wuhan and Chongqing scored higher in selfreported psychopathy than their female counterparts, $t$ Wuhan $(131)=5.02, p<.001, d=0.88,95 \% \mathrm{CI}=[0.3636,0.8364] ; t$ Chongqing $(132)=3.69, p<.001, d=0.64,95 \% \mathrm{CI}=[0.1809$, 0.5991]. However, there was no interaction between Group and Gender, $F<1$.

To examine whether psychopathy is related to the adoption of life history strategy, we used psychopathy scores to predict temporal discounting choice (100 yuan today $=1 ; 1000 \mathrm{yu}-$ $\mathrm{an}=2$ ) in a logistics regression analysis. In both groups, we found that the psychopathy score was a positive and significant predictor of life history strategy: Wuhan participants: Nagelkerke $\mathrm{R}^{2}=.124$, Wald $\chi 2(1, N=133)=11.63$, $p=.001$, odds ratio $=2.41,95 \% \mathrm{CI}=[1.454,3.994]$; Chongqing participants: Nagelkerke $\mathrm{R}^{2}=.235$, Wald $\chi 2(1$, $N=134)=15.47, p<.001$, odds ratio $=4.59,95 \%$ $\mathrm{CI}=[2.149,9.818]$. Next, we analyzed males and females
Fig. 1 The percentage of the smaller-sooner option and largerlater option responses is shown separately for Wuhan and Chongqing participants

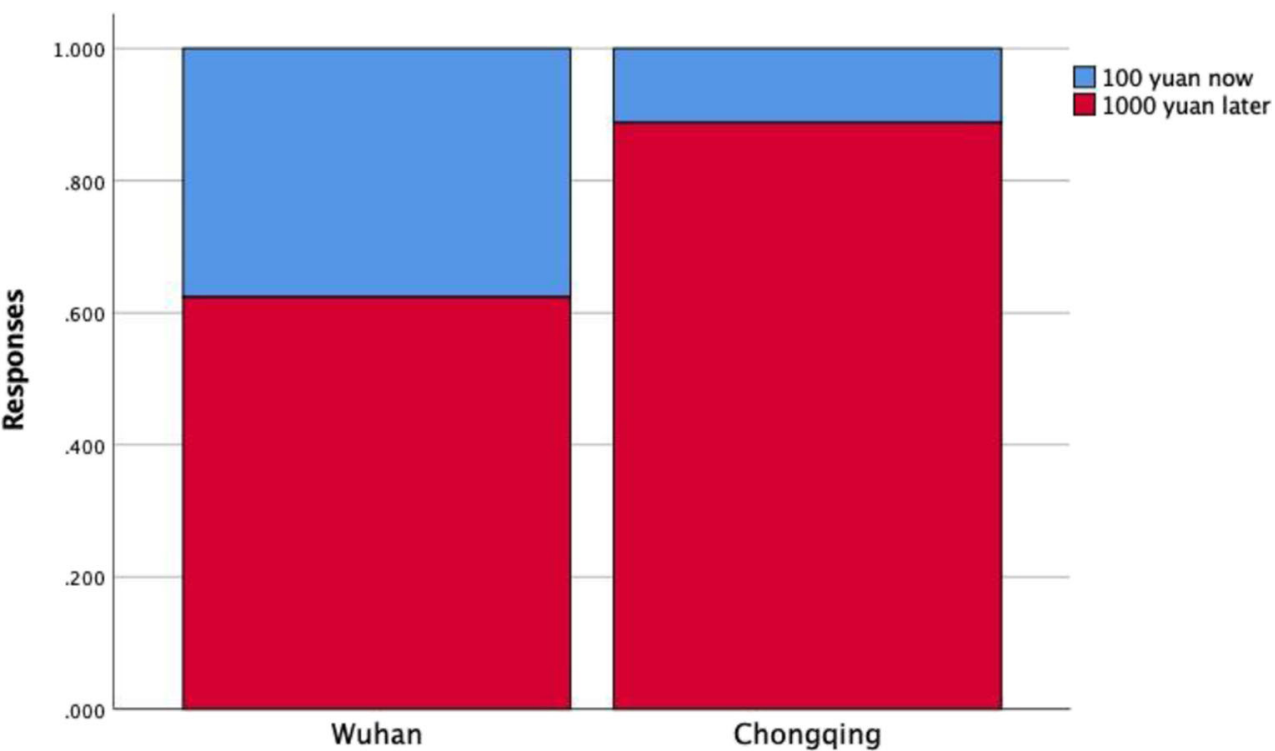


Table 2 Descriptive statistics and sex difference tests

\begin{tabular}{|c|c|c|c|c|c|c|}
\hline & \multicolumn{2}{|c|}{ Overall } & \multicolumn{2}{|l|}{ Men } & \multicolumn{2}{|c|}{ Women } \\
\hline & Mean & $\mathrm{SD}$ & Mean & $\mathrm{SD}$ & Mean & SD \\
\hline Wuhan & 2.56 & 0.75 & 2.88 & 0.84 & 2.27 & 0.51 \\
\hline Chongqing & 2.14 & 0.64 & 2.36 & 0.77 & 1.97 & 0.44 \\
\hline
\end{tabular}

separately to evaluate the replicability of this model. For Wuhan participants, the psychopathy effect was localized to both men (Nagelkerke $\mathrm{R}^{2}=.094$, Wald $\chi 2(1, \mathrm{~N}=133)=4.36$, $p=.037$, odds ratio $=1.95,95 \% \mathrm{CI}=[1.042,3.661])$ and women (Nagelkerke $\mathrm{R}^{2}=.182$, Wald $\chi 2(1, N=69)=7.955$, $p=.005$, odds ratio $=5.58,95 \% \mathrm{CI}=[1.690,18.435]$. For Chongqing participants, the psychopathy effect was also localized to both men (Nagelkerke $\mathrm{R}^{2}=.197$, Wald $\chi 2(1, N=$ $59)=6.731, p=.009$, odds ratio $=3.27,95 \% \mathrm{CI}=[1.336$, $8.005])$ and women (Nagelkerke $\mathrm{R}^{2}=.244$, Wald $\chi 2(1, N=$ $75)=6.107, p=.013$, odds ratio $=9.81,95 \% \mathrm{CI}=[1.604$, 60.017]).

\section{Discussion}

Across two studies involving 831 participants and using different measures of psychopathy and life history strategy, the present research investigated the two variables during the COVID-19 lockdown period of Wuhan. We provided consistent evidence that participants from Wuhan, the initial epicenter of the virus, displayed more psychopathic traits and were more likely to adopt a faster life strategy than those from Chongqing. Study 1 found that Wuhan participants scored higher on the Psychopathy Subscale from the Dirty Dozen Scale and lower on the Mini-K indexing a faster life strategy than those from Chongqing city. There were also gender differences in the associations among the variables. Additionally, there was a positive relationship between psychopathy and life strategy in both groups. Study 2 replicated most findings by using different measures of psychopathy and life strategy, which attenuated common method biases resulting from pronounced idiosyncrasies in the specific measures employed. We did so by gauging the psychopathic traits using the Psychopathy Subscale from the Short Dark Triad Scale and conceptualizing life history strategy as discounting future outcomes. In addition, the analyses of sex differences provided further evidence for the hypotheses that there are significant differences between males and females on the psychopathic traits.

According to Life History Theory, individuals show a high degree of variation in life history speed in response to rapidly changing environments (Belsky, Steinberg, \& Draper, 1991;
Chisholm, 1999; Figueredo, Vasquez, Brumbach, \& Schneider, 2004; Galipaud \& Kokko, 2020). For instance, Chen and $\mathrm{Qu}$ (2017) found that people may use procrastination as a fast life history trait to adapt themselves to an unpredictable and uncertain environment, in which their investments in time and effort for the future would be wasted. Based on this theorization, we predict that individuals from Wuhan, who are more affected by the pandemic, would adapt to the chaotic and disruptive environment by enacting a faster life strategy. Results of Mini-K and smaller-sooner, largerlater monetary dilemma largely confirmed our hypothesis. We found that people showed various life history strategies which are contingent on environment conditions. In other words, the seriousness of coronavirus COVID-19 pandemic can explain unique variance in the emergence of life history strategies among Chinese people. In comparison to Chongqing people, Wuhan's 11 million residents spent tenweek in strict lockdown conditions. Lockdown, an extreme social distancing intervention, has been shown to exert detrimental effects on economy, society, health, and psychology (Cao et al., 2020; Muruganandam, Neelamegam, Menon, Alexander, \& Chaturvedi, 2020; Paolini, Maricchiolo, Pacilli, \& Pagliaro, 2020). For instance, Cellini, Canale, Mioni, and Costa (2020) found that forcing people into home confinement was significantly associated with higher perceived anxiety, depression, and stress levels, which, in turn, was associated with a lower sleep quality. Thus, the lack of predictability and stability such as the date for a significant lifting of lockdown restrictions, the containment for coronavirus disease, and the food supply during the lockdown period may lead Wuhan people to activate a faster life strategy to optimize their resource use in this disadvantaged environment with respect to their Chongqing counterparts who were less affected by the virus.

There is considerable empirical support for the notion that experiences of childhood environmental unpredictability and harshness can influence people's proneness to discounting future outcomes in favor of a higher orientation towards immediate rewards such as desires for earlier marriage and first reproduction (Chen \& Chang, 2012; Međedović, 2019). Concurring with an emerging line of literature on extended life history plasticity, our results offer additional supporting evidence for the idea that people's life history strategies may shift following exposure to ecological and environmental changes. Therefore, experience of early childhood might not be the sole factor in influencing one's life history. Developmental environments with highly unpredictable future consequences such as the coronavirus pandemic can also foster the emergence of a fast life-history pattern. These findings are important because if life history strategy is flexible and malleable, it may support effective interventions during diverse stages of life in the human development. 
Variations in psychopathy have also been documented in our study. Previous research typically finds that psychopathy is a relatively strong indicator of a faster life strategy as evidenced through reduced self-control, a high interpersonal antagonism, selfishness, and other representations of antisocial tendencies (Jonason et al., 2010; Jonason, Icho, \& Ireland, 2016). In line with these findings, we found that Wuhan participants, who lived in a harsher and a more unpredictable environment during the lockdown period, displayed a significantly higher level of psychopathy than Chongqing participants and that there was a correlation between life history strategy and psychopathy in both groups. In their evolutionary analysis of personality disorders within the framework of theory, Del Giudice (2014) sketched four main causal pathways for how life history traits contribute to the development of psychopathy or even the onset of mental disorders. These causal pathways can be described as follows: 1) adaptive life history-related traits may be regarded as symptoms, 2) life-history related traits may be expressed at maladaptive levels, 3) adaptive strategies may yield individually maladaptive outcomes, and 4) adaptive life-history-related traits may increase vulnerability to dysfunction (Del Giudice, 2014, p. 269). Thus, while the adoption of a fast life strategy is biologically adaptive, it may impose cumulative burden on physical and psychological health from a longterm perspective, with personality traits and behaviors such as psychopathy. However, harsh conditions, including resource scarcity, perceived threat of COVID-19, and stringent social distance measures, may make psychopathy an adaptive life history strategy if it imbues an advantage in the particular environment. For instance, Tielbeek et al. (2017) found that the genes associated with psychopathy traits were overlapped with the genes that are responsible for early reproduction and a higher number of offspring. Such findings suggest that psychopathy personalities as a fast life strategy may have an evolutionary and reproductive advantage.

From an evolutionary perspective, females are biologically obligated to invest more of their time and energy caring for their offspring than males (Figueredo et al., 2006). Consistent with this theorization, there is considerable empirical evidence suggesting that men follow a faster life strategy than women vis-à-vis psychopathic traits. The results of this research partly replicated the gender differences in terms of life history theory and psychopathy. We found that male participants did not show significant differences from female participants in the future-discounting monetary dilemma. Both men and women in the two groups demonstrated almost the same delayed reward-oriented pattern and were willing to wait for a payout. One possible reason for the lack of difference might be that a single-item measurement is not sufficiently sensitive to capture the sex differences (also noted by Jonason et al., 2010). Future endeavors should use more expansive measures of temporal discounting such as the Consideration of Future Consequences Scale (Strathman, Gleicher, Boninger, \& Edwards, 1994).

The results notwithstanding, there are several potential limitations of the present study. The most salient limitation is that the research mainly relies on cross-sectional correlational design, posing a problem for causality. In other words, there is no way to determine the causal relationship between the study variables. Ideally future research should use an experimental design and examine whether activating thinking about coronavirus can change people's dark personality traits and their life history strategy. Second, the sample consisted of a monocultural sample, especially those from the most impacted region (e.g., Wuhan), which may invoke the issue of the generalizability of the research findings. Thus, it is unclear whether our findings can generalize to other countries which are less affected by the pandemic. Third, self-report measures may cause potential common method variance and may limit our interpretation of the data. A 360-degree appraisal instrument to assess the congruence between participants' self-ratings and ratings by their family members and coworkers during the pandemic might offer convergent validity and complementary evidence for the current findings. Fourth, the psychological mechanism underlying the fast life strategy related to the pandemic is unclear. One possible reason is that the pandemic has had important repercussions for the mental health of the population. For instance, Pulcu et al. (2014) found that individuals who reported higher levels of depression showed a greater preference for immediate reward. Such mechanisms warrant future investigation. Finally, due to financial and time constraint associated with this research program and the coronavirus situation, we did not collect much social demographic information which may also contributed to the observed effect. Future research using a greater range of predictors would allow for the use of more sophisticated statistical models, such as multiple regression, which could perhaps result in a model explaining a greater proportion of performance variance.

Acknowledgments The authors thank the anonymous reviewers for their careful reading of our manuscript and their many insightful comments and suggestions.

Data Availability Statement The data that support the findings of this study are available from the corresponding author upon reasonable request.

Funding This work was supported by the Fundamental Research Funds for the Central Universities, Southwest University (SWU1909753) and Social Science Foundation of Chongqing Municipality of China (2019BS020).

\section{Declarations}

Informed Consent Informed consent was obtained from all participants. 
Conflict of Interest The authors declared no conflict of interest.

Ethical Approval All procedures performed in studies involving human participants were in accordance with the ethical standards of the institutional and/or national research committee and with the 1964 Helsinki declaration and its later amendments or comparable ethical standards.

\section{References}

Apicella, C., Norenzayan, A., \& Henrich, J. (2020). Beyond WEIRD: A review of the last decade and a look ahead to the global laboratory of the future. Evolution and Human Behavior, 41(5), 319-329.

Belsky, J., Schlomer, G. L., \& Ellis, B. J. (2012). Beyond cumulative risk: Distinguishing harshness and unpredictability as determinants of parenting and early life history strategy. Developmental Psychology, 48, 662-673.

Belsky, J., Steinberg, L., \& Draper, P. (1991). Childhood experience, interpersonal development, and reproductive strategy: An evolutionary theory of socialization. Child Development, 62, 647-670.

Buchtel, E. E., Guan, Y., Peng, Q., Su, Y., Sang, B., Chen, S. X., \& Bond, M. H. (2015). Immorality east and west: Are immoral behaviors especially harmful, or especially uncivilized? Personality and Social Psychology Bulletin, 41, 1382-1394.

Cao, W., Fang, Z., Hou, G., Han, M., Xu, X., Dong, J., \& Zheng, J. (2020). The psychological impact of the COVID-19 epidemic on college students in China. Psychiatry Research, 287, 112934.

Cellini, N., Canale, N., Mioni, G., \& Costa, S. (2020). Changes in sleep pattern, sense of time and digital media use during COVID-19 lockdown in Italy. Journal of Sleep Research, 29, e13074.

Chen, B. B., \& Chang, L. (2012). Adaptive insecure attachment and resource control strategies during middle childhood. International Journal of Behavioral Development, 36, 389-397.

Chen, B. B., \& Qu, W. (2017). Life history strategies and procrastination: The role of environmental unpredictability. Personality and Individual Differences, 117, 23-29.

Chen, H. P., Zhao, X. L., Zeng, M., Li, J. W., Ren, X., Zhang, M. N., Liu, Y. D., \& Yang, J. (2020). Collective self-esteem and perceived stress among the non-infected general public in China during the 2019 coronavirus pandemic: A multiple mediation model. Personality and Individual Differences, 168, 110308. https://doi. org/10.1016/j.paid.2020.110308.

Chisholm, J. S. (1999). Death, hope and sex: Steps to an evolutionary ecology of mind and morality. New York: Cambridge University Press.

Cleckley, H. (1941). The mask of sanity: An attempt to reinterpret the socalled psychopathic personality. Oxford, England: Mosby.

Copping, L. T., \& Campbell, A. (2015). The environment and life history strategies: Neighborhood and individual-level models. Evolution and Human Behavior, 36, 182-190.

Crawford, C. (2000). Evolutionary psychology: Counting babies or studying information processing mechanisms. Annals of the New York Academy of Sciences, 907, 21-38.

Del Giudice, M. (2009). Sex, attachment, and the development of reproductive strategies. Behavioral and Brain Sciences, 32(1), 36-37.

Del Giudice, M. (2014). An evolutionary life history framework for psychopathology. Psychological Inquiry, 25, 261-300.

Del Giudice, M., Gangestad, S. W., \& Kaplan, H. S. (2015). Life history theory and evolutionary psychology. In D. M. Buss (Ed.), The handbook of evolutionary psychology (2nd ed., pp. 88-114). New York: Wiley Foundations.

Dunkel, C. S., Hertler, S. C., Mathes, E. W., \& de Baca, T. C. (2019). Projective tests as indicators of life history strategy: Evidence using
Loevinger's sentence completion test. Current Psychology, 1-8. https://doi.org/10.1007/s12144-019-00443-2.

Figueredo, A. J., Woodley of Menie, M. A., \& Jacobs, W. J. (2015). The general factor of personality: A hierarchical life history model. In: D. M. Buss (Ed.), The handbook of evolutionary psychology (2nd ed.). (pp. 943-967). New York: Wiley Integrations.

Figueredo, A. J., Vasquez, G., Brumbach, B. H., \& Schneider, S. M. (2004). The heritability of life history strategy: The k-factor, covitality, and personality. Social Biology, 51(3-4), 121-143.

Figueredo, A. J., Vásquez, G., Brumbach, B. H., Schneider, S. M. R., Sefcek, J. A., Tal, I. R., et al. (2006). Consilience and life history theory: From genes to brain to reproductive strategy. Developmental Review, 26, 243-275.

Galipaud, M., \& Kokko, H. (2020). Adaptation and plasticity in lifehistory theory: How to derive predictions. Evolution and Human Behavior, 41, 493-501.

Garofalo, C., Neumann, C. S., Kosson, D. S., \& Velotti, P. (2020). Psychopathy and emotion dysregulation: More than meets the eye. Psychiatry Research, 290, 113160.

Geary, D. C. (2005). The origin of the mind: Evolution of brain, cognition, and general intelligence. Washington: American Psychological Association Press.

Geng, Y. G., Sun, Q. B., Huang, J. Y., Zhu, Y. Z., \& Han, X. H. (2015). Dirty dozen and short dark triad: A Chinese validation of two brief measures of the dark triad. Chinese Journal of Clinical Psychology, 23(2), 246-250.

Griskevicius, V., Ackerman, J. M., Cantú, S. M., Delton, A. W., Robertson, T. E., Simpson, J. A., Thompson, M. E., \& Tybur, J. M. (2013). When the economy falters do people spend or save?: Responses to resource scar resource scarcity depend on childhood environments. Psychological Science, 24, 197-205.

Griskevicius, V., Tybur, J. M., Delton, A. W., \& Robertson, T. E. (2011). The influence of mortality and socioeconomic status on risk and delayed rewards: A life history theory approach. Journal of Personality and Social Psychology, 100, 1015-1026.

Hare, R. D. (1991). The psychopathy checklist-revised (PCL-R). Toronto, Ontario: Multi Health Systems.

Hurst, J. E., \& Kavanagh, P. S. (2017). Life history strategies and psychopathology: The faster the life strategies, the more symptoms of psychopathology. Evolution and Human Behavior, 38(1), 1-8.

Jonason, P. K., Icho, A., \& Ireland, K. (2016). Resources, harshness, and unpredictability: The socioeconomic conditions associated with the dark triad traits. Evolutionary Psychology, 14, 1-11.

Jonason, P. K., Koenig, B. L., \& Tost, J. (2010). Living a fast life. Human Nature, 21(4), 428-442.

Jonason, P. K., Li, N. P., Webster, G. W., \& Schmitt, D. P. (2009). The dark triad: Facilitating short-term mating in men. European Journal of Personality, 23, 5-18.

Jonason, P. K., \& Webster, G. D. (2010). The dirty dozen: A concise measure of the dark triad. Psychological Assessment, 22(2), 420 432.

Jonason, P. K., Webster, G. D., Schmitt, D. P., Li, N. P., \& Crysel, L. (2012). The antihero in popular culture: Life history theory and the dark triad personality traits. Review of General Psychology, 16(2), 192-199.

Jonason, P. K., Zeigler-Hill, V., \& Baldacchino, J. (2017). Before and after: Personality pathology, childhood conditions, and life history outcomes. Personality and Individual Differences, 116, 38-43.

Jones, D. N., \& Paulhus, D. L. (2014). Introducing the short dark triad (SD3) a brief measure of dark personality traits. Assessment, 21(1), 28-41.

Kruger, D. J., Fernandes, H. B., Cupal, S., \& Homish, G. G. (2019). Life history variation and the preparedness paradox. Evolutionary Behavioral Sciences, 13(3), 242-253. 
Kruger, D. J., Reischl, T., \& Zimmerman, M. A. (2008). Time perspective as a mechanism for functional developmental adaptation. Journal of Social, Evolutionary, and Cultural Psychology, 2, 1-22.

Larsson, H., Andershed, H., \& Lichtenstein, P. (2006). A genetic factor explains most of the variation in the psychopathic personality. Journal of Abnormal Psychology, 115(2), 221-230.

Lau, H., Khosrawipour, V., Kocbach, P., Mikolajczyk, A., Schubert, J., Bania, J., et al. (2020). The positive impact of lockdown in Wuhan on containing the COVID-19 outbreak in China. Journal of Travel Medicine, 27(3), taaa037.

Li, W., Zhang, Y., Wang, J., Ozaki, A., Wang, Q., Chen, Y., \& Jiang, Q. (2021). Association of Home Quarantine and Mental Health among Teenagers in Wuhan, China, during the COVID-19 pandemic. JAMA Pediatrics. https://doi.org/10.1001/jamapediatrics.2020. 5499.

Lu, H. J., \& Chang, L. (2019). Aggression and risk-taking as adaptive implementations of fast life history strategy. Developmental Science, 22(5), e12827.

Lu, J. G., Liu, X. L., Liao, H., \& Wang, L. (2020). Disentangling stereotypes from social reality: Astrological stereotypes and discrimination in China. Journal of Personality and Social Psychology. Advance online publication, 119, 1359-1379. https://doi.org/10. 1037/pspi0000237.

MacArthur, R. H., \& Wilson, E. O. (1967). The theory of island geography. Princeton: Princeton University Press.

McDonald, M. M., Donnellan, M. B., \& Navarrete, C. D. (2012). A life history approach to understanding the dark triad. Personality and Individual Differences, 52(5), 601-605.

Međedović, J. (2019). Life history in a postconflict society. Human Nature, 30(1), 59-70.

Miller, J. D., Vize, C., Crowe, M. L., \& Lynam, D. R. (2019). A critical appraisal of the dark-triad literature and suggestions for moving forward. Current Directions in Psychological Science, 28(4), 353360

Muruganandam, P., Neelamegam, S., Menon, V., Alexander, J., \& Chaturvedi, S. K. (2020). COVID-19 and severe mental illness: Impact on patients and its relation with their awareness about COVID-19. Psychiatry Research, 291, 113265.

Ni, M. Y., Yang, L., Leung, C. M., Li, N., Yao, X. I., Wang, Y., et al. (2020). Mental health, risk factors, and social media use during the COVID-19 epidemic and cordon sanitaire among the community and health professionals in Wuhan, China: Cross-sectional survey. JMIR Mental Health, 7(5), e19009.

Olderbak, S., \& Figueredo, A. J. (2009). Predicting romantic relationship satisfaction from life history strategy. Personality and Individual Differences, 46(5-6), 604-610.

Paolini, D., Maricchiolo, F., Pacilli, M. G., \& Pagliaro, S. (2020). COVID-19 lockdown in Italy: The role of social identification and social and political trust on well-being and distress. Current Psychology, 1-8. https://doi.org/10.1007/s12144-020-01141-0.

Paulhus, D. L., \& Williams, K. M. (2002). The dark triad of personality: Narcissism, Machiavellianism, and psychopathy. Journal of Research in Personality, 36(6), 556-563.
Pulcu, E., Trotter, P. D., Thomas, E. J., McFarquhar, M., Juhász, G., Sahakian, B. J., et al. (2014). Temporal discounting in major depressive disorder. Psychological Medicine, 44(9), 1825-1834.

Read, D., \& Read, N. L. (2004). Time-discounting over the lifetime. Organizational Behavior and Human Decision Processes, 94, 22 32.

Richardson, G. B., Placek, C., Srinivas, V., Jayakrishna, P., Quinlan, R., \& Madhivanan, P. (2020). Environmental stress and human life history strategy development in rural and peri-urban South India. Evolution and Human Behavior, 41, 244-252.

Sheppard, P., Pearce, M. S., \& Sear, R. (2016). How does childhood socioeconomic hardship affect reproductive strategy? Pathways of development. American Journal of Human Biology, 28, 356-363.

Sherman, R. A., Figueredo, A. J., \& Funder, D. C. (2013). The behavioral correlates of overall and distinctive life history strategy. Journal of Personality and Social Psychology, 105, 873-888.

Sng, O., Neuberg, S. L., Varnum, M. E., \& Kenrick, D. T. (2017). The crowded life is a slow life: Population density and life history strategy. Journal of Personality and Social Psychology, 112(5), 736754.

Stearns, S. C., \& Rodrigues, A. M. (2020). On the use of "life history theory" in evolutionary psychology. Evolution and Human Behavior, 41, 474-485.

Strathman, A., Gleicher, F., Boninger, D. S., \& Edwards, C. S. (1994). The consideration of future consequences: Weighing immediate and distant outcomes of behavior. Journal of Personality and Social Psychology, 66, 742-752.

Taylor, J., Loney, B. R., Bobadilla, L., Iacono, W. G., \& McGue, M. (2003). Genetic and environmental influences on psychopathy trait dimensions in a community sample of male twins. Journal of Abnormal Child Psychology, 31(6), 633-645.

Tielbeek, J. J., Johansson, A., Polderman, T. J., Rautiainen, M. R., Jansen, P., Taylor, M., et al. (2017). Genome-wide association studies of a broad spectrum of antisocial behavior. JAMA Psychiatry, 74(12), 1242-1250.

Tuvblad, C., Wang, P., Patrick, C. J., Berntsen, L., Raine, A., \& Baker, L. A. (2019). Genetic and environmental influences on disinhibition, boldness, and meanness as assessed by the triarchic psychopathy measure in 19-20-year-old twins. Psychological Medicine, 49(9), $1500-1509$.

Wang, Y., Lin, Z., Hou, B., \& Sun, S. (2017). The intrinsic mechanism of life history trade-offs: The mediating role of control striving. Acta Psychologica Sinica, 49(6), 783-793.

Wilson, E. O. (1975). Sociobiology: The new synthesis. Cambridge: Harvard University Press.

Zhong, B., Huang, Y., \& Liu, Q. (2021). Mental health toll from the coronavirus: Social media usage reveals Wuhan residents' depression and secondary trauma in the COVID-19 outbreak. Computers in Human Behavior, 114, 106524.

Publisher's Note Springer Nature remains neutral with regard to jurisdictional claims in published maps and institutional affiliations. 